\title{
Association of temporomandibular dysfunction with the 102T-C polymorphism in the serotonin receptor gene in Brazilian patients
}

\author{
Luciana Venâncio Secches de Freitas ${ }^{1}$, Ana Cláudia Polli Lopes², Vânia Belintani Piatto², \\ José Victor Maniglia ${ }^{1}$
}

\author{
${ }_{1}^{1}$ Department of Otolaryngology and Head and Neck Surgery, Faculty of Medicine \\ of São José do Rio Preto, São Paulo, Brazil (FAMERP) \\ 2Department of Morphology, Faculty of Medicine of São José do Rio Preto, São Paulo, \\ Brazil (FAMERP)
}

Submitted: 14 June 2011

Accepted: 6 December 2011

Arch Med Sci 2013; 9, 6: 1013-1018

DOI: 10.5114 /aoms.2013.39215

Copyright (c) 2013 Termedia \& Banach

\section{Abstract}

Introduction: Serotonin is a key neurotransmitter in the central nervous system. It has been suggested that serotoninergic dysfunction mediates the pathophysiology of temporomandibular dysfunction (TMD). Polymorphisms in the serotonin receptor gene (HTR2A) can alter its transcription, affecting the number of receptors in the serotoninergic system, altering nociceptive pain and hyperalgesia in TMD. The aim of this study is to investigate the association of the 102T-C polymorphism in the HTR2A gene in Brazilian patients with TMD.

Material and methods: This cross-sectional study examined 100 patients, of both genders, with TMD as index cases and 100 healthy volunteers as controls, also of both genders. DNA was extracted from peripheral blood leukocytes, and the site that encompassed the polymorphism in the HTR2A gene was amplified by polymerase chain reaction followed by restriction fragment length polymorphism (PCR-RFLP).

Results: Our results revealed that there were significantly more females among index cases compared with the control group $(p<0.05)$. The $C C$ genotype of the $102 \mathrm{~T}-\mathrm{C}$ polymorphism was more frequent in patients with TMD vs. controls (OR: 2.25; 95\% Cl: $1.13-4.46 ; p<0.05$ ).

Conclusions: The present study supports the view that the 102T-C polymorphism in the HTR2A gene is associated with TMD in this studied Brazilian population.

Key words: myofascial pain, temporomandibular joint, HTR2A gene, molecular analysis.

\section{Introduction}

Of the disorders that cause orofacial pain, the most common are disorders in the temporomandibular joint. Most patients with temporomandibular dysfunction (TMD) develop local joint pain, primarily affecting the muscles of mastication [1].

Temporomandibular dysfunction-related facial pain has been reported in $4 \%$ to $12 \%$ of the population, wherein women experience a greater frequency and severity of TMD compared with men [2,3]. The signs and symptoms of TMD are more common in patients aged 20 to 40 years [3]. It rarely progresses into severe or chronic pain (if it persists for over

\author{
Corresponding author: \\ Vânia Belintani Piatto \\ Faculdade de Medicina \\ de São José do Rio Preto \\ São Paulo, Brazil (FAMERP) \\ Departamento de Anatomia \\ Pavilhão Mário Covas $2^{\circ}$ \\ Andar \\ Laboratório de Macroscopia \\ Av. Brig. Faria Lima \\ 5416, Vila São Pedro \\ CEP: 15090-000, \\ São José do Rio Preto, \\ São Paulo, Brazil \\ Phone: +55 1732015903 \\ E-mail: vbpiatto@gmail.com
}


6 months) and may be associated with psychological disorders $[4,5]$.

Recently, genetic factors have been implicated in the development of pain in masticatory muscles, causing myofascial pain syndrome of the stomatognathic system-particularly those that are related to polymorphisms in the serotonin receptor gene (HTR2A) [6-8]. Serotonin (5-hydroxytryptamine $5-\mathrm{HT}$ ), a neurotransmitter in the central nervous system, regulates several physiological and visceral functions. Thus, abnormalities in the serotoninergic system underlie many human illnesses, such as depression, headache, epilepsy, obsessive-compulsive disorder, affective disorders, sleep apnea, and TMD [7-10].

5-Hydroxytryptamine is considered the most important neurotransmitter that regulates endogenous mechanisms of pain [11, 12]. A peripheral mechanism has been proposed to be the cause of chronic muscle pain, because mechanical overload and the consequent muscle hypoxia and microcirculation disorders have been implicated as causes of chronic myalgia due to the sensitization and activation of muscle nociceptors by algogenic substances $[13,14]$.

These findings suggest that 5-HT in deep craniofacial tissue induces peripheral sensitization, leading to the development of hyperalgesic nociceptive responses, and mediates the development and maintenance of chronic orofacial pain in $\operatorname{TMD}[7,8]$. Thus, this neurotransmitter modulates nociceptive pain and hyperalgesia using central and peripheral mechanisms [7, 8, 15-17].

Like other neurotransmitters, serotonin is released into the synaptic cleft and exerts its effects on specific receptors on the postsynaptic membrane. 5-Hydroxytryptamine acts through a large family of 5-HT receptors, of which the 5-HT2 receptors comprise 3 subtypes - the 5-HT2A, 5-HT2B, and $5-\mathrm{HT} 2 \mathrm{C}$ receptors, which are similar in molecular structure, pharmacology, and signaling $[18,19]$. Some receptor subtypes in central and peripheral nervous tissue modulate pain. The 5 -HT2A receptors in postsynaptic terminals mediate serotonininduced hyperalgesia and are associated with the potentiation of inflammatory pain in various diseases that are caused by dysfunction of the serotoninergic system, particularly TMD $[7,8]$.

Polymorphisms in the HTR2A gene are associated with many diseases, including TMD, that affect the serotoninergic system. Thus, changes in serotoninergic neurotransmitters can lead to alterations in muscular tone. Recently, a silent polymorphism in the HTR2A gene was identified, defined by a $T$-to- $C$ transition at position 102 in exon 1, in $36.5 \%$ of patients with TMD [6].

The 102T-C polymorphism might be a functional polymorphism, because the $T$ and $C$ alleles determine gene expression - the $C$ allele, compared with the $T$ allele, decreases gene expression and, consequently, the amount of 5-HT2A receptors [20]. On declines in the amount of postsynaptic receptors, the concentration of serotonin in the synaptic cleft increases; thus, the resulting increase in serotonin reuptake into the presynaptic terminal reduces postsynaptic serotonin levels. These low serotonin levels are insufficient to stimulate the central descending analgesic system, triggering sensations of pain or hyperalgesia in TMD [6-8].

This study aimed to investigate the association of the $102 T-C$ polymorphism in the HTR2A gene in Brazilian patients with temporomandibular dysfunction.

\section{Material and methods}

We studied 100 index cases with TMD (44 males and 56 females, age range 17 to 76 years) who were admitted consecutively to the Department of Otolaryngology and Head and Neck Surgery, Faculty of Medicine of São José do Rio Preto, São Paulo, Brazil (FAMERP), between May 2009 and December 2010. The diagnosis of TMD was based on a questionnaire and clinical investigation, using data from the Table Procedures Clinical Investigation for TMD. Both methods are in accordance with the American Academy of Orofacial Pain [21].

For case selection, the following criteria were considered: Inclusion criteria: 1) Presence of muscle or joint pain for more than 30 days and not exceeding 6 months. 2) Presence of noises (clicks) in the temporomandibular joint. 3) Asymmetrical mandibular movements. All the patients had to show all three inclusion criteria simultaneously. Exclusion criteria: Patients with somatic, rheumatological, neurological, or psychiatric illnesses, mental retardation, alcoholism or drug dependence were excluded.

The 100 control subjects (78 males and $22 \mathrm{fe}$ males, age range 18 to 63 years) were included based on the following simultaneous criteria: 1) no joint or muscle pain, 2) absence of noises (clicks) in the temporomandibular joint, and 3) symmetrical mandibular movements. Similarly, patients with mental retardation, drug or alcohol dependence, or somatic, rheumatological, neurological, or psychiatric illnesses were excluded.

The patients and control subjects were Caucasian, from the same geographic area - São Paulo State, (Brazil) - and grouped by age: adolescents (11 to 17 years), young adults (18 to 40 years), adults (41 to 65 years), and elderly (> 65 years) [22].

This study was approved by the Research Ethics Committee (FAMERP) (\#393/2008).

\section{Clinical investigation}

For the clinical investigation, 4 basic procedures were performed to diagnose TMD: measurements 
of the extent and symmetry of mandibular movements; examination of joint palpation and facial muscles to identify the anatomical origin of the pain; auscultation of the joint during functional movements to determine the presence of joint noise; and analysis of occlusion [21].

\section{Molecular analysis}

Genomic DNA was isolated from peripheral blood leukocytes using the Illustra Blood Genomic Prep Mini Spin Kit (GE Healthcare UK Limited ${ }^{\mathrm{TM}}$, UK) as per the manufacturer's protocol. To detect the 102T-C (GenBank NM_000621.3; rs\#6313) polymorphism, nuclear DNA fragments that encompassed the polymorphic site in the HTR2A gene (MIM ID *182135) were amplified by PCR and digested with $10 \mathrm{U} \mathrm{Mspl}$ (New England Biolab ${ }^{\circledR}$ ) for $2.5 \mathrm{~h}$ at $37^{\circ} \mathrm{C}[6]$.

\section{Polymerase chain reation conditions}

Standard polymerase chain reaction (PCR) was performed in $25 \mu \mathrm{l}$, containing $200 \mathrm{ng}$ genomic DNA, 10 pmol of each primer, and FideliTaq ${ }^{\text {TM }}$ PCR Master Mix (2x) (GE Healthcare UK Limited ${ }^{\mathrm{TM}}$, UK), as per the manufacturer's protocol. Published primer sequences were used to analyze the $102 T$-C polymorphism [6], and PCR was performed as follows: initial denaturation at $94^{\circ} \mathrm{C}$ for $3 \mathrm{~min}$, followed by 35 cycles of denaturation at $94^{\circ} \mathrm{C}$ for $1 \mathrm{~min}$, annealing at $60^{\circ} \mathrm{C}$ for $1 \mathrm{~min}$, and extension at $72^{\circ} \mathrm{C}$ for $2 \mathrm{~min}$, followed by a final extension for $10 \mathrm{~min}$ at $72^{\circ} \mathrm{C}$.

The products from the PCR reaction were analyzed by electrophoresis on a $2 \%$ agarose gel in $1 \mathrm{X}$ TBE buffer. The $102 T$ allele was represented by an uncut 342-bp PCR product, and the 102C allele consisted of 2 fragments of $217 \mathrm{bp}$ and $125 \mathrm{bp}$.

To avoid bias in the molecular analysis and final results, all DNA samples were analyzed without knowledge of the patients' clinical characteristics.

\section{Statistical analysis}

Statistical analyses were performed using Graph Pad InStat, version 3.00 (Graph Pad Software Inc, San Diego, California, USA). Qualitative variables were expressed as a percentage (\%). Continuous variables were expressed as a mean $(M)$ and standard deviation (SD), and because the mean age was not normally distributed between both groups, it was compared using the Mann-Whitney test. Correlations between variables were assessed using the $\chi^{2}$ test and odds ratios with a confidence interval of $95 \%(95 \% \mathrm{Cl})$ at a significance level of $5 \%$. All samples were tested for Hardy-Weinberg equilibrium.

\section{Results}

Of the 100 index cases, 44 (44\%) were male and 56 (56\%) were female. Males ranged in age from 17 to
76 years (mean: 37.9 years; SD \pm 12.8 ), and females ranged in age from 18 to 68 years (mean: 34.4 years; SD \pm 12.8 ).

Of the 100 control patients, 78 (78\%) were male and $22(22 \%)$ were female. Control males ranged in age from 18 to 63 years (mean: 35.4 years; SD \pm 11.6 ), and control females were aged 19 to 54 years (mean: 32.5 years; SD \pm 11.6 ).

With regard to the demographics (Table I), there were more females (56\%) in the index case group and more males in the control group (78\%) $(p<0.0001)$. In both groups, the percentages of those in the young adult and adult age brackets combined were highest $-97 \%$ and $100 \%$, respectively - but this difference was not significant compared with the other age groups $(p>0.05)$. The relationship between mean age of both groups was not significant $(p>0.05)$.

Regarding the genotype frequencies, the TT genotype (wild-type) was more prevalent in the control group (37\%), and the CC genotype (polymorphic) was more common in the index cases (30\%) ( $p=0.015)$ (Table II).

There were more females (44\%) in the index group and more males (67\%) in the control group with the TT/TC genotypes, and $18 \%$ and $11 \%$ of males, respectively, harbored the CC genotype. The relationship between gender and genotype was significant in both groups $(p=0.0015)$ (Table III).

Table I. Demographics of index cases $(n=100)$ and the control group $(n=100)$

\begin{tabular}{|c|c|c|c|}
\hline Variables & Index cases & Controls & Value of $p$ \\
\hline Gender & $n(\%)$ & $n(\%)$ & \multirow[t]{3}{*}{$<0.0001^{*}$} \\
\hline Male & $44(44)$ & $78(78)$ & \\
\hline Female & $56(56)$ & $22(22)$ & \\
\hline Age range & $n(\%)$ & $n(\%)$ & \multirow[t]{5}{*}{$0.9080^{*}$} \\
\hline Adolescent & $1(1)$ & $0(0)$ & \\
\hline Young adult & $65(65)$ & $69(69)$ & \\
\hline Adult & $32(32)$ & $31(31)$ & \\
\hline Elderly & $2(2)$ & $0(0)$ & \\
\hline \multirow[t]{2}{*}{ Age [years] } & $M \pm S D$ & $M \pm S D$ & \multirow[t]{2}{*}{$0.5808^{\dagger}$} \\
\hline & $35.9 \pm 12.9$ & $34.7 \pm 11.6$ & \\
\hline
\end{tabular}

${ }^{*} \chi^{2}$ test, ${ }^{\dagger}$ Mann-Whitney test, $M \pm S D-$ mean \pm standard deviation

Table II. Distribution of genotypes of the 102T-C polymorphism in the HTR $2 A$ gene in index cases and controls

\begin{tabular}{|c|c|c|c|}
\hline Genotype & $\begin{array}{c}\text { Index cases } \\
n(\%)\end{array}$ & $\begin{array}{c}\text { Controls } \\
n(\%)\end{array}$ & Value of $p^{\star}$ \\
\hline$T T$ & $16(16)$ & $37(37)$ & 0.0015 \\
\hline$T C$ & $54(54)$ & $47(47)$ & \\
\hline$C C$ & $30(30)$ & $16(16)$ & \\
\hline
\end{tabular}


Table III. Distribution of genders in index cases and control group with regard to the $102 \mathrm{~T}$-C polymorphism in the 5-HTR2A gene

\begin{tabular}{|lccccc|}
\hline Genotype & \multicolumn{2}{c}{ Index cases } & \multicolumn{2}{c|}{ Controls } & Value of $p^{*}$ \\
\cline { 2 - 4 } & Male, $n(\%)$ & Female, $n(\%)$ & Male, $n(\%)$ & Female, $n(\%)$ & \\
\hline$T T$ & $7(7)$ & $9(9)$ & $27(27)$ & $10(10)$ & 0.0028 \\
\hline$T C$ & $20(20)$ & $35(35)$ & $40(40)$ & $7(07)$ & \\
\hline$C C$ & $17(17)$ & $12(12)$ & $11(11)$ & $5(5)$ & \\
\hline
\end{tabular}

Table IV. Genotypic relationship between index cases and control group for the 102T-C polymorphism in the HTR2A gene

\begin{tabular}{|lcccc|}
\hline Genotype (Index cases $\times$ controls) & Odds ratio (OR) & $95 \% \mathrm{Cl}$ & $\chi^{2^{*}}$ & Value of $p^{*}$ \\
\hline$T T(16 \times 37)$ & 0.32 & $0.16-0.63$ & 10.27 & 0.0014 \\
\hline$T C(54 \times 47)$ & 1.32 & $0.76-2.31$ & 0.72 & 0.3961 \\
\hline$C C(30 \times 16)$ & 2.25 & $1.13-4.46$ & 4.77 & 0.0289 \\
\hline
\end{tabular}

$95 \% \mathrm{Cl}-95 \%$ confidence interval, ${ }^{*} \chi^{2}$ test

Table V. Allelic relationship between index cases and control group for the $102 T-C$ polymorphism in the HTR2A gene

\begin{tabular}{|lcccc|}
\hline Alleles (Index cases/controls) & Odds ratio (OR) & $95 \% \mathrm{Cl}$ & $\chi^{2^{*}}$ & Value of $p^{*}$ \\
\hline$T(86 / 121)$ & 0.49 & $0.33-0.73$ & 11.57 & 0.0007 \\
\hline$C(114 / 79)$ & 2.03 & $1.36-3.02$ & & \\
\hline
\end{tabular}

$95 \% \mathrm{Cl}-95 \%$ confidence interval, ${ }^{*} \chi^{2}$ test

The index cases had a significantly lower frequency of the TT genotype compared with the control group $(p=0.014)$. However, the index cases had the CC genotype with a higher frequency when compared with controls $(p=0.0289)$. There was no significant difference in the frequency of the TC genotype between groups $(p>0.05)$ (Table IV).

With regard to allele frequencies, the index cases had a significantly lower frequency of the $T$ allele (wild-type) and a higher frequency of the $C$ allele (polymorphic) compared with controls $(p=0.0007)$ (Table V).

The allelic frequencies for the index cases were $T=0.43$ and $C=0.57$ and $T=0.60$ and $C=0.40$ for the controls. Both groups were tested for HardyWeinberg equilibrium, bearing no significant differences $(p>0.05)$ between the observed and expected genotypic values for the $102 T-C$ polymorphism (index cases $\chi^{2}=1.03, \mathrm{~d} f=1, p=0.31$; controls $\chi^{2}=0.03, \mathrm{~d} f=1, p=0.87$ ).

\section{Discussion}

The molecular basis of temporomandibular dysfunction (TMD) is still unknown and merits further research. Genetic factors have been implicated in the development of pain in masticatory muscles, causing myofascial pain of the stomatognathic system, especially the factors that are associated with polymorphisms in the serotonin receptor gene (HTR2A) [7, 8].

The 5 -HT2A receptor is an essential component of the serotoninergic system, and its expression is under genetic control. Thus, polymorphisms in genes encoding the receptor can affect its function and thus modulate serotoninergic activity, causing changes in muscle tone [18].

This study evaluated the prevalence of the $102 T-C$ polymorphism in the HTR2A gene in patients with and without TMD, because there have been no Brazilian studies on this topic; only one study in the international literature has reported the frequency of this polymorphism and its association with TMD [6], highlighting the significance of this study.

To assess the results of genetic association studies, the test and control groups should have the same ethnic and geographical origins, because of the genetic basis of diseases, such as polymorphic configurations, which can vary between regions and populations. The influence of ethnic and geographic diversity can be extensive and should be considered in genetic studies [6, 22-26]. In this study, despite the significant miscegenation in Brazil, only Caucasian patients and controls were included, all of whom were from the same geographical area.

It is widely accepted that TMD is more prevalent in females, affecting those aged 20 to 40 years [3]. Epidemiological studies of the Brazilian population observed a high prevalence of females among patients with TMD, the majority of whom were in the age range $21-30$ years $[27,28]$. Because women tend to seek treatment for their TMD more frequently than men, attempts have been made to explain these differences in terms of behavioral, psychosocial, hormonal, and constitutional disparities, although no conclusive results have been generated $[3,5]$. 
In this study, based on the literature [3, 5, 27, $28]$, there was a predominance of females in the TMD group, outnumbering men 1.2 : 1 ; but in the control group, males predominated by $3.5: 1$. The average age of females in the TMD group (34.4 years) and control group (32.5 years) was slightly higher than what has been described in the Brazilian literature $[27,28]$ but is within the range of the international literature $[3,5]$.

In an international study that associated the $102 T-C$ polymorphism in the HTR2A gene to TMD, 63 patients and 54 controls of both genders were analyzed; the CC genotype (polymorphic) was expressed in $36.5 \%$ of patients with TMD, and the TT genotype (wild-type) was noted in $27.8 \%$ of controls [6].

Similarly, we compared the genotypic and allelic frequencies between patient and control groups. The CC genotype (polymorphic) was more prevalent among index cases (30\%), and the TT genotype (wild-type) predominated in the control group (37\%). Consequently, the $\mathrm{C}$ allele was more frequent in the TMD group, and the T allele was more frequent in the control group.

Recent findings [1, 6-8] indicate that the variant genotypes of HTR2A gene, which have disparate levels of activity, could affect or modify serotoninergic activity by reducing the number of postsynaptic receptors, resulting in a lower concentration of serotonin in the extracellular space - particularly active serotonin [1, 6-8].

Low serotonin levels are insufficient to stimulate the central descending analgesic system, triggering the feeling of pain or hyperalgesia in the TMD. Thus, these genotypic variants may have different molecular functions in TMD; alternatively, they might mediate its pathogenesis or determine a genetic predisposition to it, although TMD does not seem to have familial patterns of pathology [1, 6-8].

Like many other functional pain syndromes, however, the underlying mechanisms that contribute to craniofacial pain in TMD remain poorly understood. This lack of understanding is compounded by the often poor correlation between the severity of TMDrelated complaints of pain and definitive pathophysiological evidence, such as tissue damage and degeneration, in painful tissues. Thus, in some patients with TMD, pain has been proposed to result from altered processing of pain by the central nervous system, which is attributable to specific heritable genes, such as HTR2A gene [1].

Despite the predominance of females in the TMD group and males in the control group in this study, there was a higher percentage of males with the CC genotype in both groups $-17 \%$ and $11 \%$, respectively. In the reference study [6], despite the predominance of males in both groups, there was no mention of the predominant gender for the poly- morphic genotype $(C C)$; thus, it was not possible to determine whether these gender differences explain the findings in our study with regard to the genotype distribution.

Serotonin and its receptors have been the focus of many reports and reviews, but only one has examined their interaction with TMD [6]. Other genetic studies should be performed to determine the complexities of TMD and develop new approaches for this dysfunction, which can result from the interaction between multiple genes and environmental factors. Such knowledge can increase our understanding of the physiology and pathophysiology of myofascial pain and facilitate the discovery of the molecular causes of TMD, providing new perspectives on early diagnosis and pharmacological therapies and stimulating research to determine how the serotoninergic system influences the modulation of pain [1]. The genetic association with TMD strengthens the serotoninergic system dysfunction hypothesis with regard to TMD pathogenesis $[1,6]$.

The potential limitations of these data merit consideration, because despite our positive findings, they should be interpreted with caution and must be corroborated by independent and multicenter studies to determine the real prevalence of the $102 T-C$ polymorphism in the HTR2A gene and its association with TMD in the Brazilian population. Therefore, it is necessary to validate our data in prospective studies with a larger population size. Second, as our study was conducted in a sample of Brazilian patients, extrapolation of the data to other ethnic groups should be done with great caution.

In conclusion, the present findings suggest that there is evidence of an association between the 102T-C polymorphism in the HTR2A gene and TMD in this studied Brazilian population.

\section{Acknowledgments}

This investigation was supported by grants from FAMERP (BAP - 2009/2010).

\section{References}

1. Cairns BE. Pathophysiology of TMD pain-basic mechanisms and their implications for pharmacotherapy. J Oral Rehabil 2010; 37: 391-410.

2. Karibe H, Goddard G, Gear RW. Sex differences in masticatory muscle pain after chewing. J Dent Res 2003; 82: 112-6.

3. Roda RP, Bagán JV, Fernández JMD, Bazán SH, Soriano YJ. Review of temporomandibular joint pathology. Part I: Classification, epidemiology and risk factors. Med Oral Patol Circ Bucal 2007; 12: 292-8.

4. Hentschel K, Capobianco DJ, Dodick DW. Facial pain. Neurologist 2005; 11: 244-9.

5. Almășan OC, Băciuț M, Almășan HA, et al. Skeletal pattern in subjects with temporomandibular joint disorders. Arch Med Sci 2013; 9: 118-26. 
6. Mutlu N, Erdal ME, Herken H, Oz G, Bayazit YA. T102C polymorphism of the HT2A receptor gene may be associated with temporomandibular dysfunction. Oral Dis 2004; 10: 349-52.

7. Okamoto $\mathrm{K}$, Imbe $\mathrm{H}$, Tashiro $\mathrm{N}$, et al. The role of peripheral 5 HT2A and 5 HT1A receptors on ten orofacial formalin test in rats with presistent temporomandibular joint inflamation. Neuroscience 2005; 130: 465-74.

8. Okamoto K, Imbe H, Kimura A, Donishi T, Tamai Y, Senba E. Activation of central 5HT2A receptors reduces the craniofacial nociception of rats. Neuroscience 2007; 147: 1090-102.

9. Meloto CB, Serrano PO, Ribeiro-da Silva MC, RizzattiBarbosa CM. Genomics and the new perspectives for temporomandibular disorders. Arch Oral Biol 2011; 56: 1181-91.

10. Flirski M, Sobow T, Kloszewska I. Behavioural genetics of Alzheimer's disease: a comprehensive review. Arch Med Sci 2011; 7: 195-210.

11. Okamoto K, Imbe H, Kimura A, Donishi T, Tamai Y, Senba E. Activation of central $5 \mathrm{HT} 2 \mathrm{~A}$ receptors reduces the craniofacial nociception of rats. Neuroscience 2007; 147: 1090-102.

12. Green AR. Neuropharmacology of 5-hydroxytryptamine. Br J Pharmacol 2006; 147 (Suppl. 1): 145-52.

13. Oliveira MC, Pelegrini-da-Silva A, Parada CA, Tambeli CH. 5-HT acts on nociceptive primary afferents through an indirect mechanism to induce hyperalgesia in the subcutaneous tissue. Neuroscience 2007; 145: 708-14.

14. Ren K, Dubner R. Interactions between the immune and nervous systems in pain. Nat Med 2010; 16: 1267-76.

15. Sommer C. Serotonin in pain and analgesia: actions in the periphery. Mol Neurobiol 2004; 30: 117-25.

16. Suzuki R, Rygh LJ, Dickenson AH. Bad news from the brain descending 5-HT pathways that control spinal pain processing. Trends Pharmacol Sci 2004; 25: 613-7.

17. Lopez-Garcia JA. Serotonergic modulation of spinal sensory circuits. Curr Top Med Chem 2006; 6: 1987-96.

18. Barnes NM, Sharp T. A review of central $5-H T$ receptors and their function. Neuropharmacology 1999; 38: 1083-152.

19. Hoyer D, Hannon JP, Martin GR. Molecular, pharmacological and functional diversity of 5 -HT receptors. Pharmacol Biochem Behav 2002; 71: 533-54

20. Polesskaya OO, Sokolov BP. Differential expression of the " $\mathrm{C}$ " and "T" alleles of the 5-HT2A receptor gene in the temporal cortex of normal individuals and schizophrenics. J Neurosci Res 2002; 67: 812-22.

21. de Leeuw R. Orofacial pain: guidelines for assessment, diagnosis and management. 4th ed. The American Academy of Orofacial Pain. Chicago: Quintessence; 2008.

22. WHO. Ageing and Health Programme Division of Health Promotion, Education and Communication. The Hildelberg guidelines for promoting physical activity among older persons: guidelines series for healthy ageing $-I$. Heidelberg, Germany: August; 1996.

23. Mergener M, Becker RM, dos Santos AF, dos Santos GA, de Andrade FM. Influence of the interaction between environmental quality and T102C SNP in the HTR2A gene on fibromyalgia susceptibility. Rev Bras Reumatol 2011; 51: 594-602.

24. Gürsoy S, Erdal E, Herken H, Madenci E, Alasehirli B. Association of $\mathrm{T} 102 \mathrm{C}$ polymorphism of the $5-\mathrm{HT} 2 \mathrm{~A}$ receptor gene with psychiatric status in fibromyalgia syndrome. Rheumatol Int 2001; 21: 58-61.

25. Herken H, Erdal E, Mutlu N, et al. Possible association of temporomandibular joint pain and dysfunction with a polymorphism in the serotonin transporter gene. Am J Orthod Dentofacial Orthop 2001; 120: 308-13.
26. Ojima K, Watanabe N, Narita N, Narita M. Temporomandibular disorder is associated with a serotonin transporter gene polymorphism in the Japanese population. Biopsychosoc Med 2007; 10: 1-3.

27. Luz JG, Maragno IC, Martin MC. Characteristics of chief complaints of patients temporomandibular disorders in a Brazilian population. J Oral Rehabil 1997; 24: 240-3.

28. Silveira AM, Feltrin PP, Zanetti RV, Mautoni MC. Prevalence of patients harboring temporomandibular disorders in an otorhinolaryngology department. Rev Bras Otorrinolaringol 2007; 73: 528-32. 